\title{
Statistical study of bacteremia secondary to catheter (BSC) in our intensive care unit (ICU). bacteremia zero (BZ) program implementation
}

\author{
R Fernández Fernández ${ }^{*}$ MR Ramírez Puerta, O Moreno Romero, ME Yuste Ossorio, M Muñoz Garach \\ From ESICM LIVES 2015 \\ Berlin, Germany. 3-7 October 2015
}

\begin{abstract}
Introduction
The BSC infections increase mortality, complications, hospital stay and the costs. In our setting, BSC is one of the device-associated infections more common. The Alliance for Patient Safety, WHO, launched in 2004, the campaign for the prevention of infection associated to medical care though hand hygiene. The Working Group on Infectious Diseases of the Spanish Society of Intensive Care Medicine and Coronary Units (GTEI-SEMICYUC), developed the National Survey of Nosocomial Infection Surveillance (ENVIN) as a computerized record of the incidence of nosocomial infection for services or intensive care units (ICU). Were selected for monitoring those most serious and frequent nosocomial infections related to instrumentation, including ventilator-associated pneumonia, urinary tract infection associated with urethral catheterization and BSC
\end{abstract}

\section{Objectives}

We want to show the evolution of BSC: central venous catheter (CVC) and arterial (CA) in our 18-bed unit, after the implementation of $\mathrm{BZ}$ program and compare it with spanish data.

\section{Methods}

- Data from ENVIN 01.04.11 / 01.04.2015. 18 ICU beds. Rates: $\mathrm{BSC} / 100$ admitted, $\mathrm{BSC} / \mathrm{CVC}-\mathrm{CA}$. Incidence density (ID): BSC/1000ds,

$\mathrm{BSC} / 1000$ days CVC-CA

N 4198 (patients admitted to ICU), 1659 patients with CVC-CA, 17575 days of stay

(ds),11024 days of CVC, CA.

Hospital Universitario San Cecilio, Unidad Cuidados Intensivos, Granada, Spain

c 2015 Fernández Fernández et al.; This is an Open Access article distributed under the terms of the Creative Commons Attribution License (http://creativecommons.org/licenses/by/4.0), which permits unrestricted use, distribution, and reproduction in any medium, provided the original work is properly cited.
- Training and educational campaign were imparted to professionals of our unit and

Anesthesiology service (235 people). Some classes were presencial and another were by means of internet. Implementation of protocol for hand washing, technical skills about the insertion of CVC, cleaning and maintenance of catheters.

-The main objective of $\mathrm{BZ}$ project was to reduce $\mathrm{BRC}$ DI $<4$ episodes per 1000 CVC days.

\section{Results}

01.04.11-01.04.12: 3 BSC 0.29/100 admitted, 0.80/CVCCA, 0.62/1000ds, 0.96/1000

days CVC-CA. Germ A. Baumanii 33.33\%, P.mirabilis $33.33 \%$, S. Epidermidis

33.33\%. Sepsis $66.67 \%$

01.04.12-01.04.13: 7 BSC. 0.65/100 admitted, 1.61/

CVC-CA, $1.42 / 1000 \mathrm{ds}, 2.1 / 1000$

days CVC-CA. Germ S. Coagulasa negativo (SCN). Severe sepsis $28.57 \%$

01.04.13-01.04.14: 5 BSC 0.44/100 admitted, 1.08/

CVC-CA, $1.02 / 1000 \mathrm{ds}, 1.63 / 1000$

days CVC-CA. Germ S. Epidermidis. Sepsis 60\%

01.04.14-01.04.15: 3 BSC 0.31/100 admitted, 0.78/100 CVC-CA, 0.71/1000 ds,

1.07/1000 days CVC-CA. Germ: S. epidermidis. Sepsis $100 \%$.

Spain, last year: $\mathrm{N}=20799,1.59 / 100$ admitted, 2.51/ 100 pat CVC-CA, $2.10 / 1000 \mathrm{ds}$,

1.69/ 1000 days CVC-CA. Germ S. Epidermidis. Sepsis $64.85 \%$

\section{Conclusions}

We are below the level of BSC set by the SEMICYUC with fewest BSC than the rest of the country through 
the implementation of the program BZ. In the last year, we have improved our numbers because the realization of program recommendations has been monitored more intensively since in the previous two years had been a relaxation and thereby increased the numbers of BSC.

\section{Grant Acknowledgment}

UCI San Cecilio.

Published: 1 October 2015

\section{Reference}

1. [http://hws.vhebron.net/envin-helics/].

doi:10.1186/2197-425X-3-S1-A883

Cite this article as: Fernández Fernández et al:: Statistical study of bacteremia secondary to catheter (BSC) in our intensive care unit (ICU). bacteremia zero (BZ) program implementation. Intensive Care Medicine Experimental 2015 3(Suppl 1):A883.

\section{Submit your manuscript to a SpringerOpen ${ }^{\circ}$} journal and benefit from:

- Convenient online submission

- Rigorous peer review

- Immediate publication on acceptance

- Open access: articles freely available online

- High visibility within the field

- Retaining the copyright to your article

Submit your next manuscript at $\gg$ springeropen.com 